\title{
Functional Properties of $R Y R 1$ Mutations Identified in Swedish Malignant Hyperthermia and Central Core Disease Patients
}

Mirko Vukcevic ${ }^{1}{ }^{*}$, Marcus Broman ${ }^{2}{ }^{*}$, , Gunilla Islander ${ }^{2}$, Mikael Bodelsson $^{2}$, Eva Ranklev-Twetman ${ }^{2}$, Clemens R. Müller ${ }^{3}$, Susan Treves $^{1}$

*) both authors contributed in equal parts of the study

${ }^{1}$ Department of Anaesthesia and Biomedicine, Basel University Hospital, Switzerland.

${ }^{2}$ Department of Anaesthesiology and Intensive Care, Lund University Hospital, Sweden.

${ }^{3}$ Department of Human Genetics, Biocentre, University of Würzburg, Germany.

Corresponding author: Marcus Broman, MD, Consultant, Department of Anaesthesiology and Intensive Care, Lund University Hospital S-22185 Lund, Sweden.

e-mail: Marcus.Broman@skane.se

telephone: +4646171539

fax: +4646171949

Short title: Functional Properties of RYR1 Mutations 


\section{Abstract}

Background: A diagnosis of malignant hyperthermia susceptibility (MHS) by in vitro contraction testing can often only be performed at specialized laboratories far away from where the patients live. Therefore, we have designed a protocol for genetic screening of the RYR1-cDNA and for functional testing of newly identified ryanodine receptor 1 (RYR1) gene variants in B lymphocytes isolated from peripheral blood samples drawn at the local primary care centres.

Methods: B lymphocytes were isolated for the extraction of RYR1mRNA and genomic DNA and for establishment of lymphoblastoid $B$ cell lines in five patients carrying yet unclassified mutations in the RYR1. The B lymphoblastoid cell lines were used to study resting cytoplasmic calcium concentration, the peak calcium transient induced by the sarco(endo)plasmic reticulum CaATPase inhibitor thapsigargin and the dose dependent calcium release induced by the ryanodine receptor agonist 4-chloro-m-cresol.

Results: It was possible to extract mRNA for cDNA synthesis and to create B lymphocyte clones from all samples. All B lymphoblastoid cell lines carrying RYR1 candidate mutations showed significantly elevated resting cytoplasmic calcium levels as well as a shift to lower concentrations of 4-chloro-m-cresol inducing calcium release compared to controls.

Conclusions: Peripheral blood samples are stable regarding RNA and DNA extraction and establishment of lymphoblastoid B cell lines after transportation at ambient temperature over large distances by ordinary mail. Functional tests on B cells harbouring the newly identified amino acid substitutions indicate that they alter 
intracellular $\mathrm{Ca}^{2+}$ homeostasis and are most likely causative of malignant hyperthermia $(\mathrm{MH})$.

In individuals who are genetically predisposed to Malignant Hyperthermia (MHS; OMIM *145600), halogenated anaesthetics and/or suxamethonium can induce a severe decompensation of muscle calcium homeostasis leading to a life threatening crisis including hyperthermia, tachycardia, coagulation disturbances, generalised muscle rigidity, oliguria and eventually death (1). The diagnosis of MHS is traditionally made by an in vitro contraction test (IVCT). This investigation is highly invasive requiring an open muscle biopsy from $m$. quadriceps and specialized testing equipment (2).

The clinical presentation of Central Core Disease (CCD; OMIM ${ }^{*} 117000$ ) is highly variable and symptoms may vary from clinically very mild to severe congenital myopathy with hypotonia, skeletal abnormalities and scoliosis $(3,4)$.

The ryanodine receptor 1 (RYR1) is encoded by the $R Y R 1$ gene located on chromosome 19q13.1. The gene comprises 159,000 base pairs which are distributed over 106 exons. The RYR1-cDNA has a length of $15,117 \mathrm{~kb}$ and encodes a protein monomer of 5,038 amino acids $(5,6)$. More than 200 sequence variants in the $R Y R 1$ gene have been identified to date and linked to MHS, CCD other neuromuscular disorders, yet the functional impact of only a minority of these amino acid substitutions have been elucidated to date (www.emhg.org). The vast majority of these variants have been found in individual patients and their families and only a few recurrent variants account for less than $10 \%$ of the MHS subjects, each $(5,6)$.

$\mathrm{Ca}^{2+}$ is a second messenger in skeletal muscle cells. It is stored in the sarcoplasmic reticulum, an organelle whose function is intimately linked to regulating the myoplasmic $\mathrm{Ca}^{2+}$ concentration (7-11) and is 
released via a process known as excitation-contraction coupling (ECC). When the dihydropyridine receptor (DHPR), the voltage sensor on the plasmalemma, senses a change in membrane potential, it undergoes a conformational change and directly interacts with the ryanodine receptor $1 \mathrm{Ca}^{2+}$ channel, causing it to open. DHPR and RYR1 form highly organized structures on their respective membranes: four DHPR units on the transverse tubular membrane face corresponding RYR1 tetramers located on the junctional face membrane of the terminal cisternae (12). Because $\mathrm{Ca}^{2+}$ can act as a second messenger in many biological functions, its intracellular concentration is tightly regulated and maintained in a typical resting mammalian cell at about $60-120 \mathrm{nM}$, while the extracellular free $\mathrm{Ca}^{2+}$ concentration is about $2 \mathrm{mM}(8,9)$. Any alteration of $\mathrm{Ca}^{2+}$ homeostasis can affect the function of cells. In muscle cells, genetic disturbances of $\mathrm{Ca}^{2+}$ handling result in a variety of neuromuscular disorders such as MHS, CCD, some forms of Multiminicore Disease and Centronuclear Myopathy, and Brody's disease $(4,6,13)$.

Although the $R Y R 1$ is mainly expressed in striated muscle cells it is now well established that B lymphocytes also express this calcium channel $(14,15)$.

The aim of the present study was to develop an alternative protocol for diagnostic studies on $\mathrm{MH}$ individuals by transporting blood samples instead of the patients themselves to the specialized testing centre. This increases the opportunity of MHS diagnosis even if a patient's health service provider is far away from the $\mathrm{MH}$ laboratory. We designed a simple and practical protocol for the collection of blood samples to be drawn at the patients' local primary care centres. Three venous peripheral blood samples of $5 \mathrm{ml}$ each were collected in different test tubes for mRNA and genomic DNA extraction and for establishment of B lymphoblastoid cell lines. Genetic screening and functional studies were successfully performed on these samples. 


\section{Material and Methods}

\section{Clinical presentation}

With Regional Ethics Committee approval the patients participating in the study were informed by telephone and also signed a written consent to the study. All patients carried one candidate RYR1 mutation each; patient 1: p.Glu1058Lys, patient 2: p.Arg1679His, patient 3: p.His382Asn, patient 4: p.Lys1393Arg and patient 5: p.Arg2508Gly. These are the patients from a cohort of 15 Scandinavian MHS patients, who where screened for the $R Y R 1$ total coding region in our previous study (16), and found to carry a novel or yet unclassified sequence variant.

Details of the clinical presentation of the patients with the reported $R Y R 1$ amino acid substitutions are given in Table 1 and in Appendix 1.

For patients 1-4, the $\mathrm{MH}$ rank was assessed. The $\mathrm{MH}$ rank describes the qualitative likelihood, from $1=$ almost never to $6=$ almost certain, that an adverse anaesthetic event represents $\mathrm{MH}$. This clinical grading scale requires the anaesthesiologist to judge whether specific clinical signs are appropriate for the patient's medical condition, anaesthetic technique or surgical procedure (17). The MH rank scores are presented in Table 1 and in Appendix 1. Patient 5 has an established CCD diagnosis and his main symptoms are scoliosis and muscle weakness in the lower extremities. A microscopic histopathological picture of his muscle tissue is shown in Figure 1.

\section{IVCT}

Patients 1-4 had suffered serious $\mathrm{MH}$ clinical reactions and thereafter 
been tested by IVCT and classified as MHS. The CCD patient (patient 5) was tested by the IVCT as part of standard diagnostic investigations in order to establish his diagnosis and was also classified as MHS. All IVCTs were carried out at the National Swedish Malignant Hyperthermia Laboratory of Lund University Hospital according to the European Malignant Hyperthermia Group (EMHG) protocol (2). The results of the IVCTs are presented in Table 1 .

\section{Blood sampling}

The patients were provided with written information about the sampling process. Peripheral venous blood samples were drawn by the local family doctor in an EDTA tube, a PAXgene tube and in a heparin tube. The tubes were sent by normal mail without further handling or cooling to the laboratory in Würzburg, Germany, a distance up to $2000 \mathrm{~km}$ and a transportation time up to six days. Because PAXgene tubes are not normally available at Swedish primary care centres they were provided to the patients.

\section{Genetics}

Total RNA was extracted from the PAXgene tubes according to the manufacturer's instructions and genomic DNA of leukocytes from the EDTA tubes according to standard protocols. First strand cDNA was synthesized using SuperScript ${ }^{\mathrm{TM}}$ II (Invitrogen, Carlsbad, California) according to the manufacturer's instructions. Due to the size of the RYR1-mRNA, the first cDNA strand was synthesized using three mixes of specific primers. The resulting first strands were then amplified in 500-700 base pairs overlapping fragments using a second set of primers (primers sequences are available from the authors on request). Sequencing was performed by the BigDye $1.1 \mathrm{kit}$ on an ABI 3130 XL (Applied Biosystems, Darmstadt, Germany). All 
cDNA sequence variants leading to amino acid substitutions were confirmed on genomic DNA from the same patient $(16,18)$.

\section{Establishment of EBV immortalized B lymphoblastoid cell lines}

B lymphocytes were isolated from the blood collected in the heparin tubes and transformed by Epstein Barr virus (EBV), as previously described (18).

\section{Functional tests}

Changes in the intracellular $\mathrm{Ca}^{2+}$ concentration $\left(\left[\mathrm{Ca}^{2+}\right]\right.$ i) of the $\mathrm{B}$ lymphoblastoid cells from patients carrying the candidate mutations and from healthy controls were assessed as previously described (14, 18 ), after loading cells with the fluorescent $\mathrm{Ca}^{2+}$ indicator fura-2/AM (5 $\mu \mathrm{M}$ final concentration). Experiments were carried out on cell populations in a thermostatted LS-50 Perkin Elmer spectrofluorimeter equipped with a magnetic stirrer. The peak increase of the $\mathrm{Ca}^{2+}$ transient obtained after addition of a given concentration of 4-chloro-m-cresol on the linear part of the fura-2 calcium sensitive curve was expressed as percentage of the peak $\mathrm{Ca}^{2+}$ released by maximal concentrations $(1000 \mu \mathrm{M})$ of 4 -chloro-m-cresol. In order to assess if the RYR1 mutation affected the size of the intracellular $\mathrm{Ca}^{2+}$ stores, the area under the curve (AUC) obtained after addition of $400 \mathrm{nM}$ thapsigargin, which represents the total amount of $\mathrm{Ca}^{2+}$ present in the rapidly releasable intracellular $\mathrm{Ca}^{2+}$ stores, was also calculated.

\section{Statistical analysis}

Statistical analysis was performed using Student's $t$ test for paired samples or ANOVA when more than two groups were compared. Origin computer program (Microcal Software, Inc., Northampton, MA, USA) was used for statistical analysis and dose response curve 
generation. The area under curve (AUC) values were calculated from the dose response curves whereas the $\mathrm{EC}_{50}$ and $\mathrm{R}_{\max }$ values were calculated from sigmoidal curve fitting of all data points. Results are expressed as mean value $( \pm$ SEM) of $n$ results, where $n$ stands for the number of measurements.

\section{Results}

Following the sampling protocol as outlined in Materials and Methods, peripheral blood samples proved to be sufficiently stable during transportation by ordinary mail at ambient temperatures over a period of up to six days for RNA and DNA extraction and establishment of lymphoblastoid B cell lines. Genetic screening for the presence of $R Y R 1$ mutations (16) and calcium measurements on $\mathrm{B}$ lymphocytes could successfully be performed on these samples.

We first examined the resting $\left[\mathrm{Ca}^{2+}\right]$ i of the B lymphocytes carrying the newly identified sequence variants and compared it to the resting $\left[\mathrm{Ca}^{2+}\right]_{\mathrm{i}}$ of healthy controls (Figure 2). All cell lines carrying a candidate mutation showed statistically significant higher resting $\left[\mathrm{Ca}^{2+}\right]_{\mathrm{i}}$ compared to cell lines from healthy controls. On the other hand, the AUC calculations of the $\mathrm{Ca}^{2+}$ transient obtained after stimulating the B lymphocytes with $400 \mathrm{nM}$ thapsigargin were all within the same range, irrespective of whether cells were obtained from controls or from individuals carrying the indicated $R Y R 1$ candidate mutations (Figure 2). These results imply that none of the mutations affect the size of the intracellular $\mathrm{Ca}^{2+}$ stores in a way that could not be compensated by the cells. Nevertheless, all the amino acid substitutions affect $\mathrm{Ca}^{2+}$ homeostasis since they cause a small but significant increase in the resting $\mathrm{Ca}^{2+}$, a result which has been previously shown for B lymphocytes from individuals with the MHS phenotype $(15,19-21)$. 
We next determined whether the newly identified mutations affect the sensitivity of $\mathrm{Ca}^{2+}$ release induced by the RYR1 agonist 4-chloro$\mathrm{m}$-cresol. Figure 3, panel A shows the typical increase in cytoplasmic $\left[\mathrm{Ca}^{2+}\right]_{\text {i }}$ obtained in control cells after the addition of $600 \mu \mathrm{M} 4$-chloro$\mathrm{m}$-cresol. The trace, which represents the mean change in fluorescence of $1.5 \times 10^{6}$ cells, shows that addition of the RYR1 agonist is accompanied by a transient increase in the $340 / 380 \mathrm{~nm}$ fluorescent ratio, which returns to resting levels within about 10 minutes. We then constructed 4-chloro-m-cresol dose response curves by calculating the peak $\mathrm{Ca}^{2+}$ released by 4-chloro-m-cresol in a population $\left(1.5 \times 10^{6}\right.$ cells) of fura- 2 loaded B-cells as a percentage of the maximum amount which could be released by $1000 \mu \mathrm{M} 4$-chloro$\mathrm{m}$-cresol. Results are given as means \pm SEM. The dose response curves from the cell lines carrying each of the candidate mutations showed a significant shift to the left compared to the curves from the cell lines from healthy controls. Table 2 shows the EC 50 values for 4chloro-m-cresol induced $\mathrm{Ca}^{2+}$ release.

\section{Discussion}

In the present study we have used a practical protocol to draw peripheral blood samples from MHS individuals at their local primary care centres in order to screen and identify $R Y R 1$ variants and to perform functional tests on the newly identified candidate mutations. Blood samples were sent by ordinary mail from different locations in Sweden to the laboratory in Würzburg, Germany, from September to January which is autumn and wintertime in Northern Europe. Thus, the samples were not exposed to extreme heat which could have compromised their viability.

Four of the substitutions described in the present report were identified in MHS patients who had developed life threatening $\mathrm{MH}$ reactions during anaesthesia (p.Glu1058Lys, p.Arg1679His, 
p.His382Asn, p.Lys1393Arg). None of these substitutions have been reported in former patients. The fifth substitution (p.Arg2508Gly) occurring in the CCD patient, has been identified before in a cohort of CCD patients from Japan (22).

Patient 1 (p.Glu1058Lys) has a certain suspicion of muscular disease (see Appendix 1) but despite large investigations a definitive diagnosis has not been found. Patients with myotonic muscle disease can react especially to suxamethone (23) and thus one could argue the reaction she experienced was not true malignant hyperthermia. However the clinical reaction scores high on the larach scale and had symptoms that are not first line in myotonic patients reacting to suxamethone and inhalational anesthetics.

In our previous study (16) the substitution p.Arg1679His was found in 1 of 150 healthy anonymised German subjects and p.Lys1393Arg in 1 of 100 Swedish subjects leaving the possibility of rare polymorphisms. However, the population prevalence of a genetic $\mathrm{MH}$ disposition has never been studied. Therefore, these control subjects could likewise be as yet unidentified $\mathrm{MH}$ carriers. Ideal controls would be individuals with known IVCT status MHN of course.

Following the report by Sei et al (14) that also B lymphocytes express a functional type 1 RYR, we and others have exploited such a system to investigate the functional effect of candidate mutations linked to MHS and CCD phenotypes (15, 18-20, 21-22, 24-27). These studies have revealed that most $\mathrm{MH}$ causing mutations disturb normal calcium homeostasis by (i) shifting the sensitivity of pharmacological RYR1 activation to lower agonist concentrations and (ii) by causing an increase in the resting $\left[\mathrm{Ca}^{2+}\right]_{\mathrm{i}}(15,20-21,24)$. Overall, the results compared well to the IVCT data of the same subjects. Likewise, the results of the present study demonstrate a significant alteration of intracellular $\mathrm{Ca}^{2+}$ handling for all five candidate mutations. 
The magnitude of the disturbance of the intra cellular $\mathrm{Ca}^{2+}$ homeostasis in our study is in the same range and can be compared to similar measurements in other studies (28).

Assessing $\mathrm{Ca}^{2+}$ homeostasis in the immortalized B lymphocyte system offers several advantages such as: (i) cells can be grown in large numbers, (ii) are easy to handle and (iii) can be assayed using a simple methodology such as fluorimetric analysis of cells loaded with the fluorescent $\mathrm{Ca}^{2+}$ indicator fura-2 and stimulated with the RYR1 agonist 4-chloro-m-cresol. In this context, it should be emphasized that this system is only useful for assessing $R Y R 1$ mutations and not, for example, mutations found in the alpha- 1 subunit gene encoding the DHPR, which has been found to harbour mutations in a small number of MHS families (29) since this isoform of the voltage sensor is probably not expressed in B lymphocytes.

We conclude from our results that the RYR1 amino acid substitutions studied are highly likely to be associated with the MH status in these patients. According to the guidelines of the EMHG (30) RYR1 mutations should only be regarded as causative of $\mathrm{MH}$ if functional tests have been performed on tissues from at least two unrelated individuals carrying the same candidate mutation. This, however, is impeded by the rareness of most $R Y R 1$ mutations.

$30 \%$ of the $\mathrm{MH}$ families will not demonstrate linkage to the $R Y R 1$ and thus will not benefit from the method of testing the ryanodine 1 receptor in the B lymphocytes $(5,16)$.

We propose our protocol as a complementary approach for the diagnosis of $\mathrm{MH}$ suspected subjects living far away from an $\mathrm{MH}$ diagnostic centre. 


\section{Funding}

This work was supported by grants 3200B0-114597 from SNF and grants from the Swiss Muscle Foundation and Association Française Contre les Myopathies. We also wish to acknowledge the support of the Departments of Anesthesia of the Basel University Hospital, Switzerland and of Lund University Hospital, Sweden.

\section{References}

1. Hopkins PM: Malignant hyperthermia. Advances in clinical management and diagnosis. Br J Anaesth 2000; 85: 118-28

2. Ording H, Brancadoro V, Cozzolino S, Ellis FR, Glauber V, Gonano EF, Halsall PJ, Hartung E, Heffron JJ, Heytens L, Kozak-Ribbens G, Kress H, Krivosic-Horber R, Lehmann-Horn F, Mortier W, Nivoche Y, Ranklev-Twetman E, Sigurdsson S, Snoeck M, Stiegliz M, Tegazzin $\mathrm{V}$, Urwuyler A, Wappler F. In vitro contracture test for diagnosis of malignant hyperthermia following the protocol of the European $\mathrm{MH}$ Group: results of testing patients surviving fulminant $\mathrm{MH}$ and unrelated low-risk subjects. The European Malignant Hyperthermia Group. Acta Anaesthesiol Scand 1997; 41: 955-66

3. Quinlivan RM, Müller C, Davis M, Laing NG, Evans GA, Dove J. Central core disease: clinical, pathological, and genetic features. Arch Dis Child 2003; 88: 1051-5

4. Treves S, Jungbluth H, Muntoni F, Zorzato F. Congenital muscle disorders with cores: the ryanodine receptor calcium channel paradigm. Curr Opin Pharmacol 2008; 8: 319-26 
5. Robinson R, Carpenter D, Shaw MA, Halsall J, Hopkins P.

Mutations in RYR1 in Malignant Hyperthermia and Central Core Disease. Hum Mutat 2006; 27: 977-89

6. Treves S, Anderson AA, Ducreux, S, Divet A, Bleunven C, Grasso

C, Paesante S, Zorzato F. Ryanodine receptor 1 mutations, dysregulation of calcium homeostasis and neuromuscular disorders. Neuromuscul Disord 2005; 15: 577-87

7. Carafoli E. Intracellular calcium homeostasis. Ann Rev Biochem 1987; 56: 395-433

8. Berridge MJ, Lipp P, Bootman MD. The versatility and universality of calcium signaling. Nat Rev Mol Cell Biol 2000; 1: 11-21

9. Berridge M, Bootman MD, Roderick HL. Calcium signaling: dynamics, homeostasis and remodeling. Nat Rev Mol Cell Biol 2003; 4: $817-21$

10. Rossi AE, Dirksen RT. Sarcoplasmic reticulum: the dynamic calcium governor of muscle. Muscle Nerve 2006; 33: 715-31

11. Divet A, Paesante S, Bleuven C, Anderson A, Treves S, Zorzato F. Novel sarco(endo)plasmic reticulum proteins and calcium homeostasis in striated muscles. J Muscle Res Cell Motil 2005; 26: 7-12

12. Protasi F, Franzini-Armstrong C, and Allen PD. Role of ryanodine receptors in the assembly of calcium release units in skeletal muscle. J Cell Biol 1998; 140: 831-42

13. Monnier N, Kozak-Ribbens G, Krivosic-Horber R, Nivoche Y, Qi D, Kraev N, Loke J, Sharma P, Tegazzin V, Figarella-Branger D, Romero N, Mezin P, Bendahan D, Payen JF, Depret T, Maclennan DH, Lunardi J. Correlations Between Genotype and Pharmacological, 
Histological, Functional and Clinical Phenotypes in Malignant Hyperthermia Susceptibility. Hum Mutat 2005; 26: 413-25

14. Sei Y, Gallagher KL, Basile AS. Skeletal muscle type ryanodine receptor is involved in calcium signaling in human B lymphocytes. J Biol Chem 1999; 274: 5995-6002

15. Girard T, Cavagna D, Padovan E, Spagnoli G, Urwuyler A, Zorzato F, Treves $\mathrm{S}$. B-lymphocytes from malignant hyperthermiasusceptible patients have an increased sensitivity to skeletal muscle ryanodine receptor activators. J Biol Chem 2001; 276: 48077-82

16. Broman M, Gehrig A, Bodelsson M, Ranklev-Twetman E, Rüffert $\mathrm{H}$, Müller C. Mutation screening of the RYR1-cDNA from peripheral B lymphocytes in 15 Swedish Malignant Hyperthermia index cases. Br J Anaesth 2009; 102: 642-9

17. Larach MG, Localio AR, Allen GC, Denborough MA, Ellis R, Gronert GA, Kaplan RF, Muldoon SM, Nelson TE, Ording H. A clinical grading scale to predict malignant hyperthermia susceptibility. Anesthesiology 1994; 80: 771-9

18. Tilgen N, Zorzato F, Halliger-Keller B, Muntoni F, Sewry C, Palmucci LM, Schneider C, Hauser E, Lehmann-Horn F, Müller CR, Treves $\mathrm{S}$. Identification of four novel mutations in the C-terminal membrane spanning domain of the ryanodine receptor 1: associating with central core disease and alteration of calcium homeostasis. Hum Mol Gen 2001;10: 2879-87

19. McKinney LC, Butler T, Mullen SP, Klein MG. Characterization of ryanodine receptor-mediated calcium release in human $\mathrm{B}$ cells: relevance to diagnostic testing for malignant hyperthermia. Anesthesiology 2006; 104: 1191-1201 
20. Lopez JR, Contreras J, Linares N, Allen PD. Hypersensitivity of malignant hyperthermia susceptible swine skeletal muscle to caffeine is mediated by high resting myoplasmic $\left[\mathrm{Ca}^{2+}\right]$. Anesthesiology 2000; 92: $1799-1806$

21. Lopez JR, Linares N, Pessah IN, Allen PD. Enhanced response to caffeine and 4-chloro-m-cresol in malignant hyperthermia susceptible muscle is related in part to chronically elevated resting $\left[\mathrm{Ca}^{2+}\right] . A m \mathrm{~J}$ Physiol Cell Physiol 2005; 288: 606-12

22. Wu S, Ibarra MC, Mclicdan MC, Murayama K, Ichihara $Y$, Kikuchi H, Nonaka I, Noguchi S, Hayashi YK, Nishino I. Central core disease is due to RYR1 mutations in more than $90 \%$ of patients. Brain 2006; 129: 1470-80

23. Driessen J. Neuromuscular and mitochondrial disorders: what is relevant to the anaesthesiologist? Curr Opin Anaesthesiol 2008; 21: 350-5

24. Ducreaux S, Zorzato F, Müller CR, Sewry C, Muntoni F, Quinlivan R, Restagno G, Girard T, Treves S: Effect of ryanodine receptor mutations on IL-6 release and intracellular calcium homeostasis in human myotubes from malignant hyperthermia susceptible individuals and patients affected by central core disease. $J$ Biol Chem 2004; 279: 43838-46

25. Ducreux S, Zorzato F, Ferreiro A, Jungbluth H, Muntoni F, Monnier N, Müller CR, Treves S. Functional properties of ryanodine receptors carrying 3 amino acid substitutions identified in patients affected by multi-minicore disease and central core disease, expressed in immortalised lymphocytes. Biochem J 2006; 395: 259-66

26. Anderson AA, Brown RL, Polster B, Pollock N, Stowell KM: Identification and biochemical characterization of a novel ryanodine 
receptor gene mutation associated with malignant hyperthermia. Anesthesiology 2008; 108: 208-15

27. Lyfenko AD, Ducreux S, Wang Y, Xu L, Zorzato F, Ferreiro A, Meissner G, Treves S, Dirksen RT. Two central core disease (CCD) deletions in the C-terminal region of RYR1 alter muscle EC coupling by distinct mechanisms. Hum Mutat 2007; 28: 61-8

28. Levano S, Vukcevic M, Singer M, Matter A, Treves S, Urwuyler A, Girard T. Increasing the number of diagnostic mutations in malignant hyperthermia. Hum Mutat 2009; 30: 590-8

29. Weiss R, O'Connell K, Flucher B, Allen P, Grabner M, Dirksen R. Functional analysis of the $\mathrm{R} 1068 \mathrm{H}$ malignant hyperthermia mutation in the DHPR reveals an unexpected influence of the III-IV loop on skeletal muscle EC coupling. Am J Physiol Cell 2004; 287: 1094-1102

30. Urwyler A, Deufel T, McCarthy T, West S. Guidelines for molecular genetic detection of susceptibility to malignant hyperthermia. Br J Anaesth 2001; 86: 283-7 


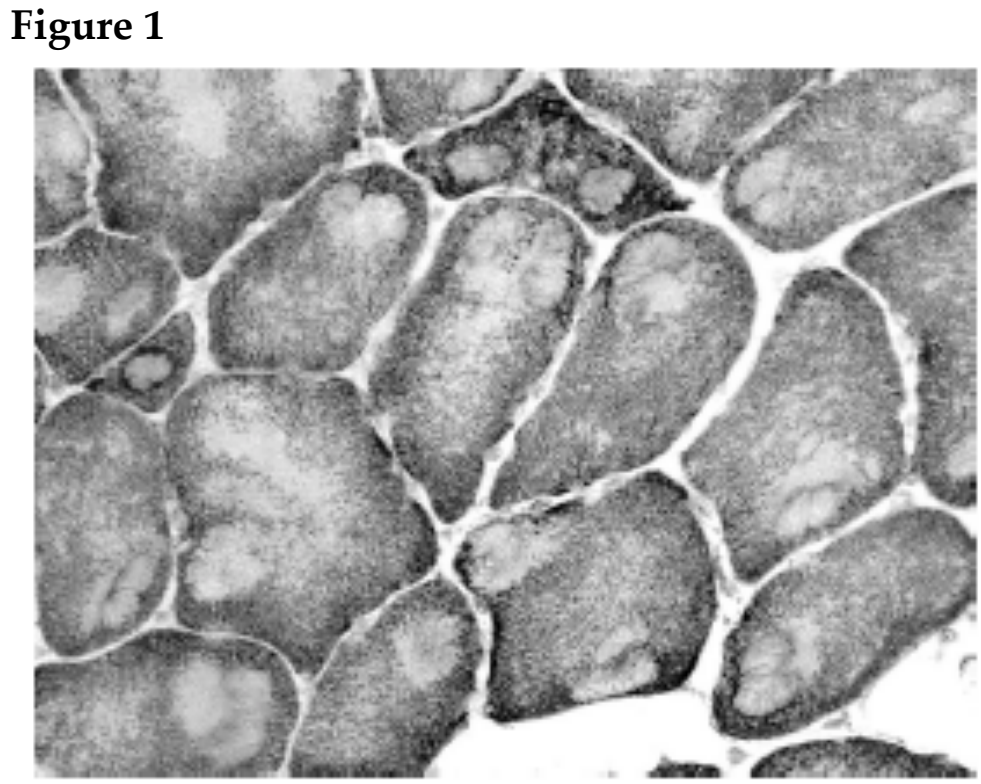

Figure 2 

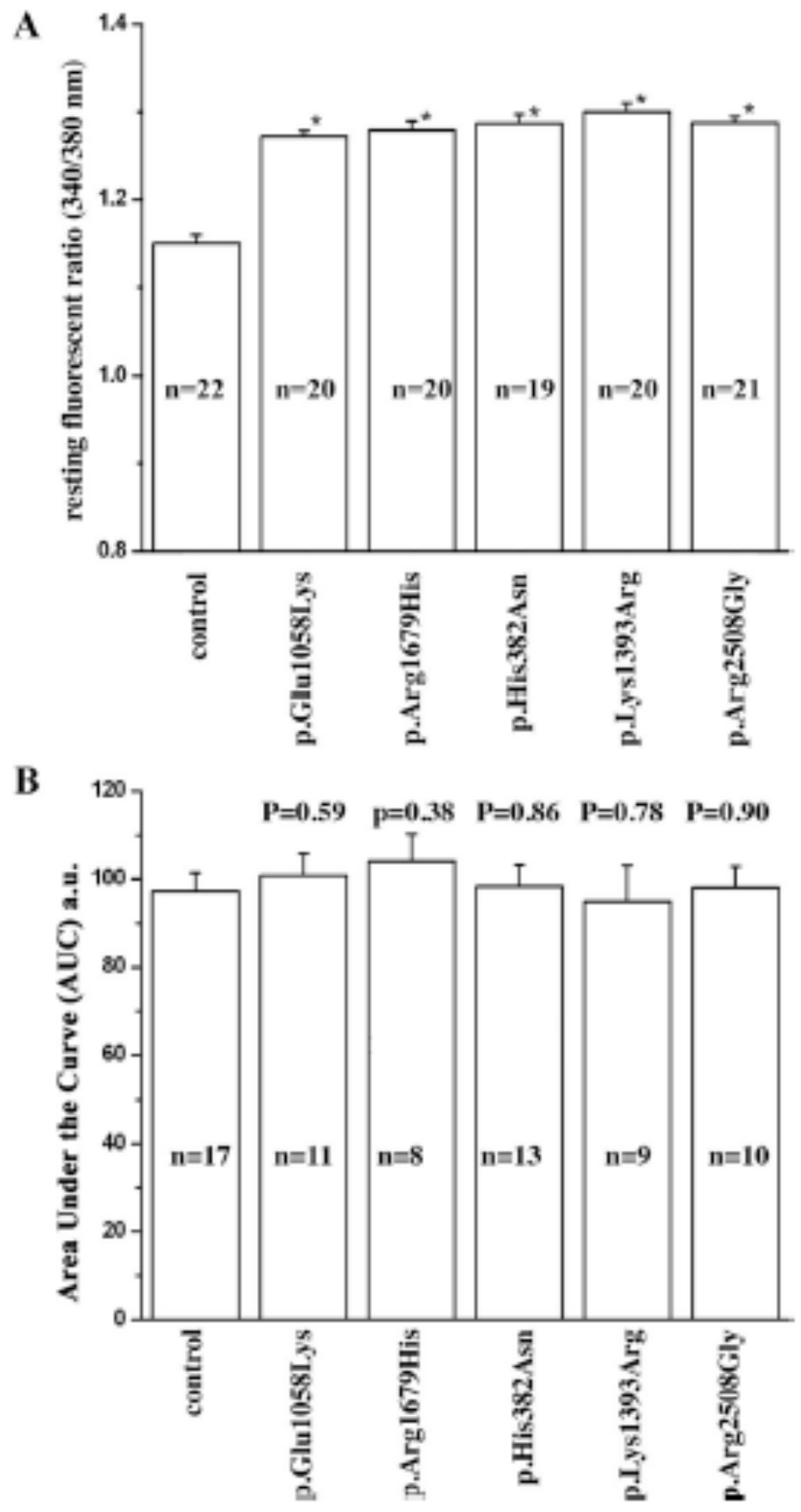


\section{Figure 3}

A
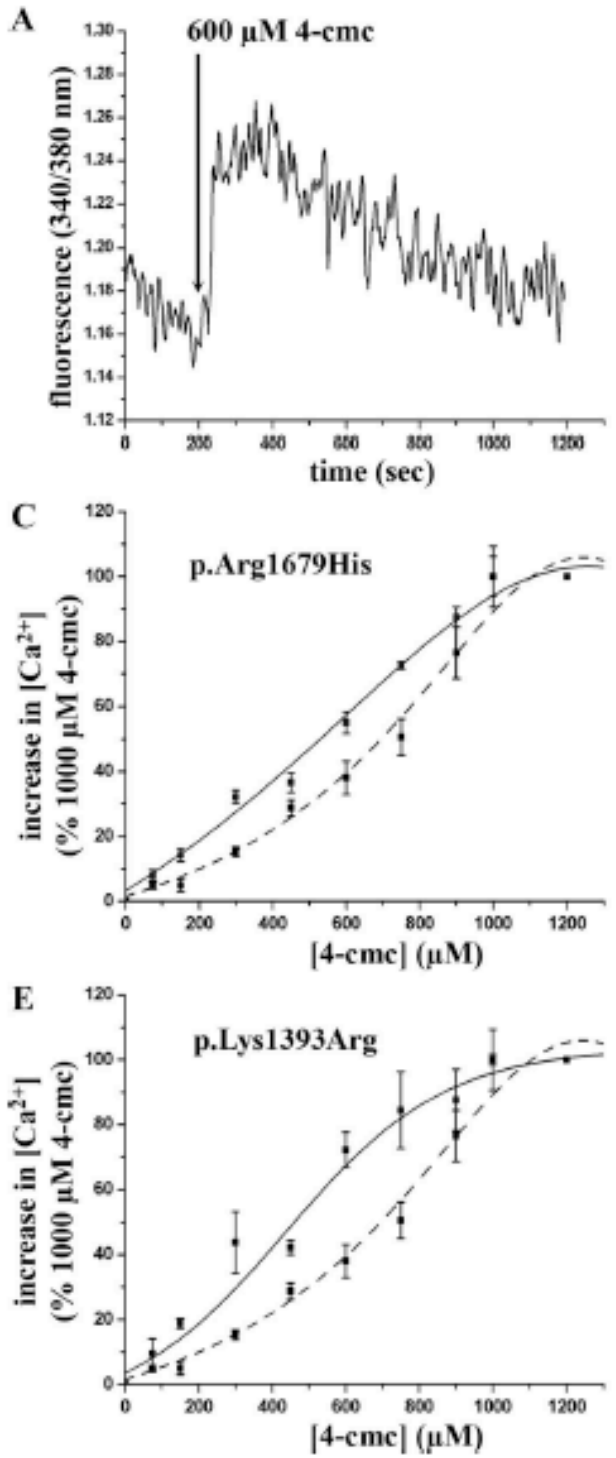
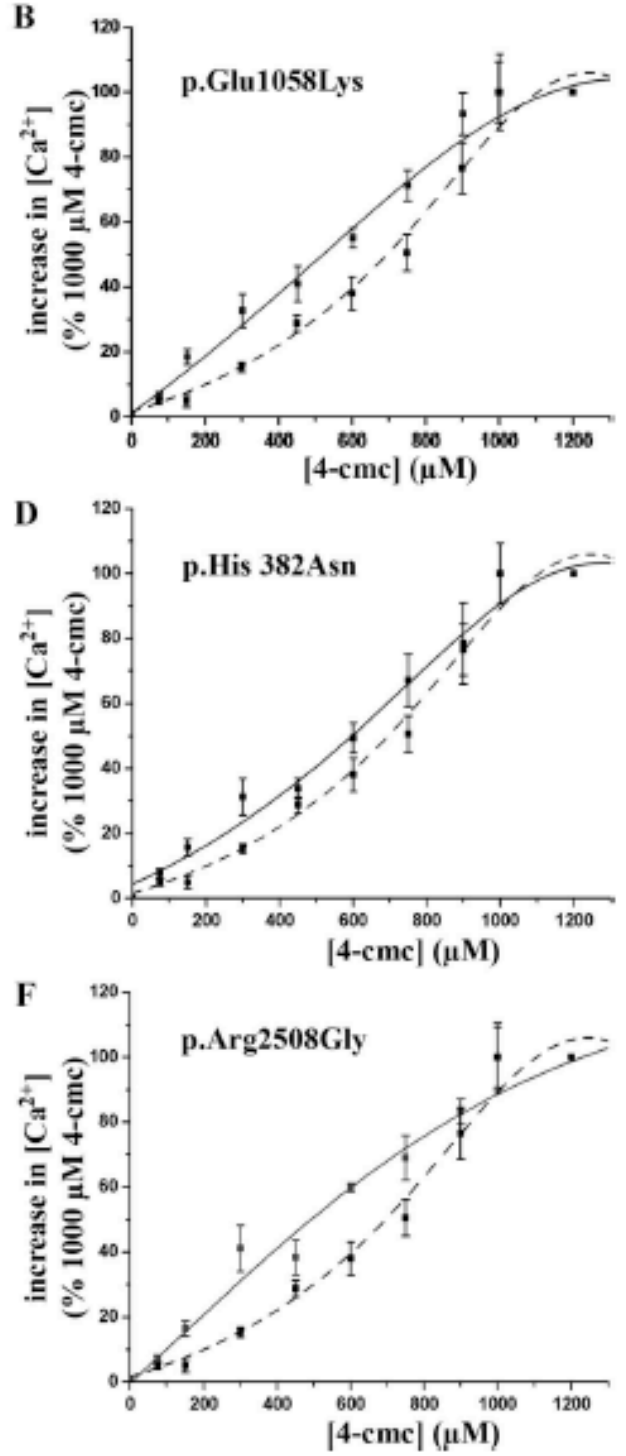